\title{
LA KHÔRA DE LOS COMUNES El rol de la comunidad local en dos paisajes productivos del Llobregat
}

\author{
Javier Rocamonde Lourido \\ Universidad: Escuela Técnica Superior de Arquitectura de Barcelona (Universidad Politécnica de Catalunya) \\ Directores de la investigación: Joaquín Sabaté y Paula Orduña \\ E-mail: rocamondelourido@gmail.com
}

\section{RESUMEN}

En este artículo se parte de la metáfora de La Khôra de los Comunes para reflexionar, desde una nueva perspectiva, sobre el protagonismo de la comunidad local en la producción y preservación de dos paisajes productivos vinculados al río Llobregat. También se reflexiona sobre los cambios en la relación de agentes y paisaje condicionados por el contexto económico, social y urbanístico.

Para comprender estos fenómenos se recurre al análisis comparativo de dos casos de estudio de ámbitos patrimoniales vinculados al río Llobregat, El Canal de la Infanta y El recinto industrial de Can Batlló.

Se concluye el artículo con una síntesis de las distintas fases de la relación entre agentes y paisaje.

Palabras clave: Khôra, Paisajes culturales, común, comunidad local, dinámicas de base

\begin{abstract}
The starting point of this article is The Khôra of the commons metaphor. First of all, we'll discuss the role of local community in the design and preservation of two productive landscapes linked to Llobregat River.

In addition, we analyse the relationship between agents and landscape that follows dynamics dependent of social, economic and urban context. To understand those phenomena two case studies are compared (Infanta canal and Can Batlló factory).

In conclusion the paper synthetizes several periods common to both case studies, that explain the relationship between actors and landscape evolution.
\end{abstract}

Key words: Khôra, cultural landscapes, common, local community and grassroots dynamics 


\section{INTRODUCCIÓN}

El título de este artículo alude a dos conceptos (khôra y comunes) surgidos en la antigüedad, y que ahora vuelven a ser pertinentes para superar las discusiones históricas de campo versus ciudad y público versus privado.

En la Antigua Grecia se designaba khôra al territorio de la Polis. En ella estaban los campos y aldeas que rodeaban el núcleo central -asty-. Sin embargo, no existía oposición entre khôra y asty, ambas pertenecían a una misma noción y una no se sometía a la otra. La khôra es también una metáfora en el Timeo de Platón que recurre a ella al descubrir la necesidad de un tercer género (triton genos) universal, que no pertenece ni al modelo inteligible, ni a la copia sensible ${ }^{1}$. Jacques Derrida (1993) la reinterpreta considerándola un receptáculo o intervalo abierto que permite que tengan lugar las cosas, los símbolos y la cultura; una suerte de espacio de oportunidad de la política (Fernández Agis 2009). En un momento de crisis ambiental en el que se da por segura la rápida tendencia a la concentración de la mayoría de la población en ciudades, la metáfora de la Khôra representa todo aquello que es necesario para sostener las formas de vida urbanas. Al menos desde un punto de vista fenomenológico, las dinámicas de la ciudad trascienden la continuidad geográfica o los límites morfológicos entre rural y urbano.

Hace 25 años Manuel de Solá-Morales (1992) advertía del error que suponía mantener de forma rígida la distinción tajante entre público y privado. Refiriéndose al caso de Barcelona, animaba a proyectar la ciudad "desde el espacio colectivo, que es mucho más y mucho menos que el espacio público, si éste lo limitamos al de propiedad administrativa." Cada vez más, la dicotomía público-privado se muestra insuficiente para comprender una realidad urbana en la que, como nos recuerda David Harvey (2013, p. 159-160), constantemente presenciamos como una élite económica se apropia de aquello producido colectivamente. Ante las nuevas reestructuraciones neoliberales del capitalismo global y con un Estado cada vez menos capaz de defender lo público, ${ }^{2}$ resulta imprescindible observar las alternativas que surgen desde la población auto-organizada para reclamar y gestionar lo común. ${ }^{3}$

Con la metáfora de la Khôra de los Comunes propongo una mirada holística a la ciudad y el territorio que presta especial atención a las dinámicas cooperativas protagonizadas por los agentes locales de base. El objetivo de este artículo es analizar desde esta perspectiva dos ámbitos patrimoniales vinculados al río Llobregat, un recurso común con gran capacidad de articulación territorial.

\section{SORE EL PATRIMONIO Y EL PRO-COMÚN}

Los ámbitos patrimoniales elegidos para este análisis son El Canal de la Infanta y el recinto industrial de Can Batlló. A principios del siglo XIX la construcción del canal expande el ámbito productivo del río Llobregat hasta el futuro emplazamiento de la fábrica. Ambos casos surgen de una necesidad productiva y resultan de la materialización física de la cooperación de diversos agentes para adaptarse a su medio físico y social. En la actualidad, más allá de su titularidad legal, en torno al canal y el recinto industrial confluyen procesos identitarios protagonizados por agentes locales de base que los reivindican como propios. Por tanto, se trata de ejemplos paradigmáticos de lo que actualmente se entiende por pro-común.

Existen dos líneas teóricas principales sobre las que se sustenta esta investigación: los paisajes culturales y los bienes comunes. Son conceptos que han suscitado bastante interés en los últimos años y cuya

\footnotetext{
1 “(En) El comienzo de nuestra exposición acerca del universo (...) diferenciamos dos principios, mientras que ahora debemos mostrar un tercer tipo adicional. En efecto, dos eran suficientes para lo dicho antes, uno supuesto como modelo, inteligible y que es siempre inmutable, el segundo como imagen del modelo, que deviene y es visible. En aquel momento, no diferenciamos una tercera clase porque consideramos que estas dos iban a ser suficientes. Ahora, sin embargo, el discurso parece estar obligado a intentar aclarar con palabras una especie difícil y vaga. ¿Qué características y qué naturaleza debemos suponer que posee? Sobre todas, la siguiente: la de ser un receptáculo de toda la generación, como si fuera su nodriza." (Platón, 360 a.C aprox.)

${ }^{2}$ Las dinámicas económicas globales desestabilizan la lógica territorial de los estados-nación ya que "el mercado global no se enfrenta a un Estado global" (Subirats y Rendueles 2016, p. 12-13).

3 "Si los bienes públicos administrados por el estado declinan o se convierten en un mero instrumento para la acumulación privada,"...

"o si el estado se retira de su administración, existe una única respuesta posible, y es que la población se auto-organice para gestionar sus propios bienes comunes. " (Harvey 2013, p. 134-135)
} 
definición aún se está discutiendo. La bibliografía es muy extensa, pero en este trabajo se presta especial atención a aquellas perspectivas que profundizan en el papel de los agentes de base en relación con los ámbitos patrimoniales aglutinadores de identidad.

\section{Del patrimonio a los paisajes culturales}

Parto de los paisajes culturales como modelo epistemológico para leer el patrimonio comprendiendo las relaciones de los agentes que lo construyeron. El valor de esta visión reside en la capacidad de comprensión global del territorio y los procesos humanos que lo modifican.

La preocupación por la preservación del patrimonio es un fenómeno que no empieza a tener relevancia hasta el siglo XIX y sobre la que aún a día de hoy existe discusión. Muchas veces el patrimonio representa una traba en la voluntad de modernización de ciudadanos, políticos o arquitectos. Ejemplo de ello es el debate surgido en Barcelona sobre la preservación del recinto industrial de Can Ricart ${ }^{4}$. Tampoco existe consenso sobre los valores a preservar o sobre qué parte de la memoria se borra y cual se transmite al futuro. Esto se refleja en las propuestas de OMA en las que se preguntan por qué solo debe ser preservado lo excepcional y lo que determina lo políticamente correcto ${ }^{5}$. La misma oficina agudiza el debate cuando propone un planeamiento que prevé a priori qué será preservado, llevando al extremo la progresiva reducción del intervalo entre la producción y la protección del patrimonio. Esto liberaría, afirman, a lo que no trascenderá, de la seriedad que implica la durabilidad ${ }^{6}$.

Desde una perspectiva histórica, se considera a Ruskin (Inglaterra 1819-1900), con una aproximación que bebe del romanticismo de la época del caminante de Friedrich; y a Eugène Viollet-le-Duc (Francia 18141879), con una visión más próxima al racionalismo y a las ideas de la ilustración heredadas de Goethe fascinado por Verona- o Heinrich Schliemann -con su obsesión por Troya- como los fundadores de la reflexión sobre la preservación del patrimonio (Sabaté Bel 2005)

En 1834 el escritor, historiador y arqueólogo Prosper Merimée (1803-1870) sucede a Ludovic Vitet como Inspector General de Monumentos Históricos en París. Es él quien encarga a Viollet-le-Duc la reforma de la abadía de Vézelay; que implica la reflexión teórica de la restauración de monumentos plasmada en el Diccionario razonado de la arquitectura francesa desde el siglo XI hasta el XVI.

En el contexto del Segundo Imperio Francés surge la oposición entre la modernización de París -promovida por Napoleón III y el Barón Haussmann- y la preservación del patrimonio medieval -defendida por Merimée, Victor Hugo o Gustavo Doré. Quizás ya en aquel entonces, como afirma Harvey (2013, p. 25) "Haussmann entendía perfectamente que su misión consistía en resolver el problema del excedente de capital y mano de obra mediante la urbanización." La dinámica que observa Harvey sienta las bases de una gran contradicción, aún sin resolver, entre las necesidades económicas del capitalismo y la voluntad de preservar y reutilizar el patrimonio.

Hasta finales del siglo XIX las consideraciones sobre la preservación del patrimonio se refieren a monumentos aislados y no se considera relevante el vínculo entre lo construido y su entorno. Prueba de ello

\footnotetext{
4 "La sociòloga Mercè Tatjer ha dirigit un estudi molt acurat i seriós - Can Ricart. Estudi patrimonial, publicat pel Grup de Patrimoni Industrial del Fòrum de la Ribera del Besòs, que penso que esdevindrà imprescindible i molt útil, quan, com espero, es consumeixi l'enderroc de Can Ricart." (Martorell 2005). Para complementar la perspectiva de la discusión es interesante ver: (Tatjer, Urbiola y Grupo de Patrimoni Industrial del Fòrum de la Ribera del Besòs 2005; Bohigas 2005; Capel 2006)

5 "Preservation's continuing emphasis on the exceptional - that which deserves preservation - creates its own distortion. The exceptional becomes the norm. There are no ideas for preserving the mediocre, the generic." (OMA 2010)

6 "The interval between the object and the moments of its preservation has decreased from about two millennia in 1882 to mere decades today. Soon, the interval will disappear. In a radical shift from the retrospective to the prospective, we will then have to decide what to preserve before we build. Some structures will be conceived to last, others to have a limited span. Preservation will introduce a deliberate phase difference in the texture of the city. We will invest ourselves more in long lasting construction - and perhaps have more fun with short-term architecture." (OMA 2003)
} 
es el constante expolio de piezas o monumentos completos desvinculados de su contexto y encerrados en recintos especializados ${ }^{7}$.

Esto cambia con la evolución del concepto de patrimonio y la aparición de paisaje cultural. Como antecedentes cabe citar el papel de los geógrafos Fiedrich Ratzel (Alemania 1844-1904), que reflexiona sobre el determinismo del medio geográfico; Otto Schlütter (Alemania 1872-1959), y su idea de landshcaft; Vidal de la Blaché (Francia 1845-1918) que teoriza sobre influencia mutua entre sociedad y naturaleza; o los sociólogos Emile Durkeim y Federic Le Play, que defendieron la relación entre paisaje y paisanaje (Sabaté Bel 2005).

A principios del siglo XX, el geógrafo Carl O. Sauer acota en La morfología del paisaje (1925) el campo de la geografía y la sistematiza como disciplina con base científica de los estudios del paisaje (land shape). Plantea una perspectiva morfológica y antropocéntrica, en la que define paisaje cultural como el resultado de la acción del hombre sobre el paisaje natural. Esta aproximación dota de protagonismo a la comunidad -como agente generador de paisaje- y al tiempo -al revelar el proceso de modificación del medio natural-.

Es muy relevante en la valorización de los paisajes culturales estadounidenses el papel del National Park Service, institución que apoya la creación de numerosos parques patrimoniales (Lowell, Blackstone, Lackawanna,...). De igual forma en Europa proliferan los paisajes revalorizados en las últimas décadas. (Sabaté Bel et al. 2001, p. 76-136). Otra prueba de la reciente relevancia del concepto es el esfuerzo de la UNESCO, desde la Convención del Patrimonio Mundial de 1972, por definirlo y distinguir sus categorías (UNESCO 2006).

La Belvedere Nota Holandesa (1999) ejemplifica el nuevo paradigma que está surgiendo en el planeamiento territorial. La identidad histórico-cultural se constituye en eje central de los instrumentos y planes de ordenación, tomando el protagonismo que en el siglo XX tiene la dinámica poblacional y el desarrollo industrial. Esta perspectiva, además de poner en valor el patrimonio, da importancia a las distintas comunidades locales, diseñando procesos de cooperación y consenso (Sabaté Bel 2007).

Es este protagonismo de los diferentes agentes involucrados en la producción del paisaje, el que sirve como nexo de unión con la otra línea de pensamiento de la que se nutre esta investigación: los bienes comunes y el pro-común.

\section{De los bienes comunes al pro-común}

En torno a muchos ámbitos patrimoniales confluyen los intereses contrapuestos del mercado y la sociedad civil: ${ }^{8}$

- Por un lado está el interés de las élites económicas en busca de la apropiación de las rentas de monopolio ${ }^{9}$ basadas en la autenticidad, unicidad y no reproducibilidad de la cultura (Harvey 2013, p. 147). Al capital también le interesan algunos de estos ámbitos al considerarlos espacios de oportunidad para el desarrollo inmobiliario recientemente revalorizados por el crecimiento de la ciudad, regeneraciones urbanas, la construcción de nuevas infraestructuras, la definición de nuevas centralidades, $\ldots$

- En los mismos ámbitos confluye también la voluntad de la comunidad local de mantener ciertas formas de vida o de preservar el patrimonio heredado en el dominio público. Los procesos identitarios

\footnotetext{
${ }^{7}$ Un ejemplo bien conocido de esta práctica son los Mármoles de Elgin, fragmentos de friso arrancados a principios del siglo XIX del Partenón de Atenas y expuestos desde 1939 en una sala habilitada para este fin en el Museo Británico.

${ }^{8}$ Ejemplo de ello puede ser el Parque Agrario del Baix Llobregat: desde una perspectiva inmobiliaria es un terreno vacante con potencial para la extensión urbana. Desde la perspectiva de los agricultores del ámbito es un delta agrario de gran fertilidad aún activo.

9 "La renta de monopolio surge porque ciertos agentes sociales pueden obtener una mayor corriente de ingresos durante un tiempo dilatado en virtud de su control exclusivo sobre algún artículo directa o indirectamente comercializable que es en ciertos aspectos cruciales único e irreproducible." (Harvey 2013, p. 139)
} 
compartidos, surgidos en torno al patrimonio, actúan de nexo de unión entre los agentes que conforman la comunidad local.

Ante este conflicto emerge de nuevo el interés por la antigua idea de los bienes comunes ${ }^{10}$. Los bienes comunes existieron en todas las comunidades desde la antigüedad hasta la revolución industrial. Generalmente se trataba de recursos naturales de primera necesidad cuyo uso y gestión eran compartidos por la comunidad. En las sociedades preindustriales estos bienes jugaban un papel muy importante ya que garantizaban la subsistencia de la gente común -aquella que no poseía tierras ya que no pertenecían al clero, a la nobleza, ni a la realeza-. Como afirma Cesar Rendueles (2016, p. 16): "Esta gestión colectiva de bienes y servicios esenciales para la comunidad no ha sido exactamente una opción para la mayor parte de los pueblos. Formaban parte de esa clase de instituciones duraderas profundamente engranadas en las condiciones materiales de subsistencia."

Otra prueba de la importancia histórica de la institución de los bienes comunes es la sentencia de Santo Tomás de Aquino: "In extrema necessitate omnia sunt communia" (En casos de extrema necesidad todo es común). El teólogo dedicó una parte de su obra Summa Teológica a legitimar la propiedad privada y el comercio, sin embargo entendía que cuando la subsistencia estaba comprometida, todo era susceptible de volverse común. Esta excepcionalidad era habitual en las sociedades pre-capitalistas que entendían que había ciertos recursos imprescindibles para la subsistencia, que debían quedar excluidos del comercio. (Subirats y Rendueles 2016, p. 39)

En Inglaterra, durante los siglos XVII y XIX, los terratenientes -convertidos en capitalistas- Ilevaron a cabo lo que Marx denominó cercamientos ${ }^{11}$ o privatización de los terrenos comunales. Este proceso dejó a los campesinos sin su medio de producción, obligándolos a depender del trabajo asalariado (deviniendo proletarios). Así se sentaron las bases para el paso del sistema económico feudal al capitalista. Desde ese entonces ya no se requeriría de la coacción física o violenta para conseguir mano de obra asalariada.

Empujados por los cercamientos, los campesinos se trasladaron a las ciudades en busca de trabajo y se llevaron consigo las prácticas comunales adaptadas a los requerimientos de la sociedad industrial. Surgirían sistemas de seguridad social, cooperativas de consumo y vivienda basadas en la auto-organización del proletariado. Estas prácticas serían asumidas más tarde por el sector público, durante el New Deal en Estados Unidos y el Estado de Bienestar en Europa, desarticulando las prácticas comunales auto organizadas (Kratzwald 2015, p. 27). Los bienes comunes caerían en el olvido durante el período de esplendor de la socialdemocracia.

A finales de los 60 Henri Lefebvre (1968) redefine las luchas anticapitalistas reivindicando el derecho colectivo a la coproducción de la ciudad. En el mismo año, Garrett Hardin publica en la revista Science un polémico artículo titulado La tragedia de los comunes (1968) en el que plantea el deterioro derivado de la utilización colectiva de un recurso escaso. Las alternativas a esta tragedia serían la privatización o el control estatal. Aunque Hardin no fue el primero en expresar esta idea, ${ }^{12}$ en el contexto de emergencia las ideas neoliberales de principios de los 70 , se utilizó su artículo para atacar las ideas socialdemócratas que habían sido hegemónicas desde finales de la segunda guerra mundial. "Dada la imposibilidad de la cooperación no autoritaria, la única alternativa no impositiva era la privatización" (Subirats y Rendueles 2016, p. 27). En ese momento surge una ola de nuevos cercamientos (Midnight Notes Collective 1990) que vuelve a hacer pertinente la reivindicación de los bienes comunes. Debido al contexto en el que emergen, los nuevos comunes se redefinen de forma más amplia y por oposición a los nuevos cercamientos o privatizaciones.

\footnotetext{
${ }^{10}$ La idea histórica de bien común alude a un recurso de uso y gestión colectivo, generalmente de carácter natural (acequias, bosques comunales, caladeros pesqueros, ríos...) y propio de comunidades rurales relativamente acotadas.

${ }^{11}$ Marx expone la noción de enclosure en capítulo de El Capital titulado La acumulación originaria (Marx 1867). En él describe el proceso secular de cierre y privatización de los terrenos comunales ingleses en los siglos XVII y XIX en favor de los terratenientes (convertidos en capitalistas). Este proceso deja a los campesinos sin su medio de producción, obligándolos a depender del trabajo asalariado (deviniendo proletarios). Así se sientan las bases para el paso del sistema económico feudal al capitalista.

12 En el capítulo 3 del Libro II de La Política, Aristóteles expone: "Lo que es común para la mayoría, es de hecho objeto del menor cuidado. Todo el mundo piensa principalmente en sí mismo, raras veces en el interés común."
} 
En 1990 la doctora en ciencias políticas Elinor Ostrom desmiente mediante un riguroso análisis (Ostrom 1990) la metáfora de Hardin, demostrando que a lo largo de la historia han existido multitud de sociedades que auto-gestionaron eficazmente sus bienes comunes. En el año 2009 su trabajo sobre el gobierno de los bienes comunes le hace merecedora del premio Nobel de Economía. La idea histórica de bien común que analiza Ostrom hace alusión a un recurso de uso y gestión colectivo, generalmente de carácter natural (acequias, bosques comunales, caladeros pesqueros,...) y propio de comunidades rurales relativamente acotadas. Sin embargo, en la actualidad, cuando hablamos del común o pro-común nos referimos a recursos más complejos que los bienes comunes históricos. El concepto actual va más allá de la titularidad legal, o la naturaleza del recurso, poniendo el acento en la acción (sufijo pro) de reivindicarlo y gestionarlo como colectivo (Hess 2008; Hardt y Negri 2009).

Aunque la capacidad del estado para defender el interés público haya quedado en entredicho, cabe plantear la construcción del pro-común como una práctica apoyada en el protagonismo de la comunidad local de base pero no desde el aislamiento. Es conveniente negociar y establecer alianzas con las administraciones públicas o incluso algunos agentes del sector privado. También es necesario articular territorialmente las distintas comunidades locales.

En el marco teórico desde el que abordo el análisis de los casos de estudio confluyen estas dos líneas de reflexión -paisajes culturales y pro-común-. Quien habita el paisaje es también quien lo produce y por tanto quien tiene el mayor potencial en la búsqueda de modelos territoriales equilibrados con voluntad emancipadora.

\section{DESVELANDO EL ROL DE LA COMUNIDAD LOCAL}

Quisiera verificar hasta qué punto el protagonismo de la comunidad local de base es indispensable en la construcción y preservación de los paisajes productivos. También trataré de demostrar que la relación de los agentes locales con el patrimonio sigue dinámicas muy dependientes del contexto económico, social y urbanístico. El análisis me permitirá establecer varios períodos que sintetizan las distintas fases evolutivas de esta relación.

Para demostrar ambas hipótesis recurro a la comparación de dos paisajes productivos vinculados al Llobregat, El Canal de la Infanta y el recinto industrial de Can Batlló.

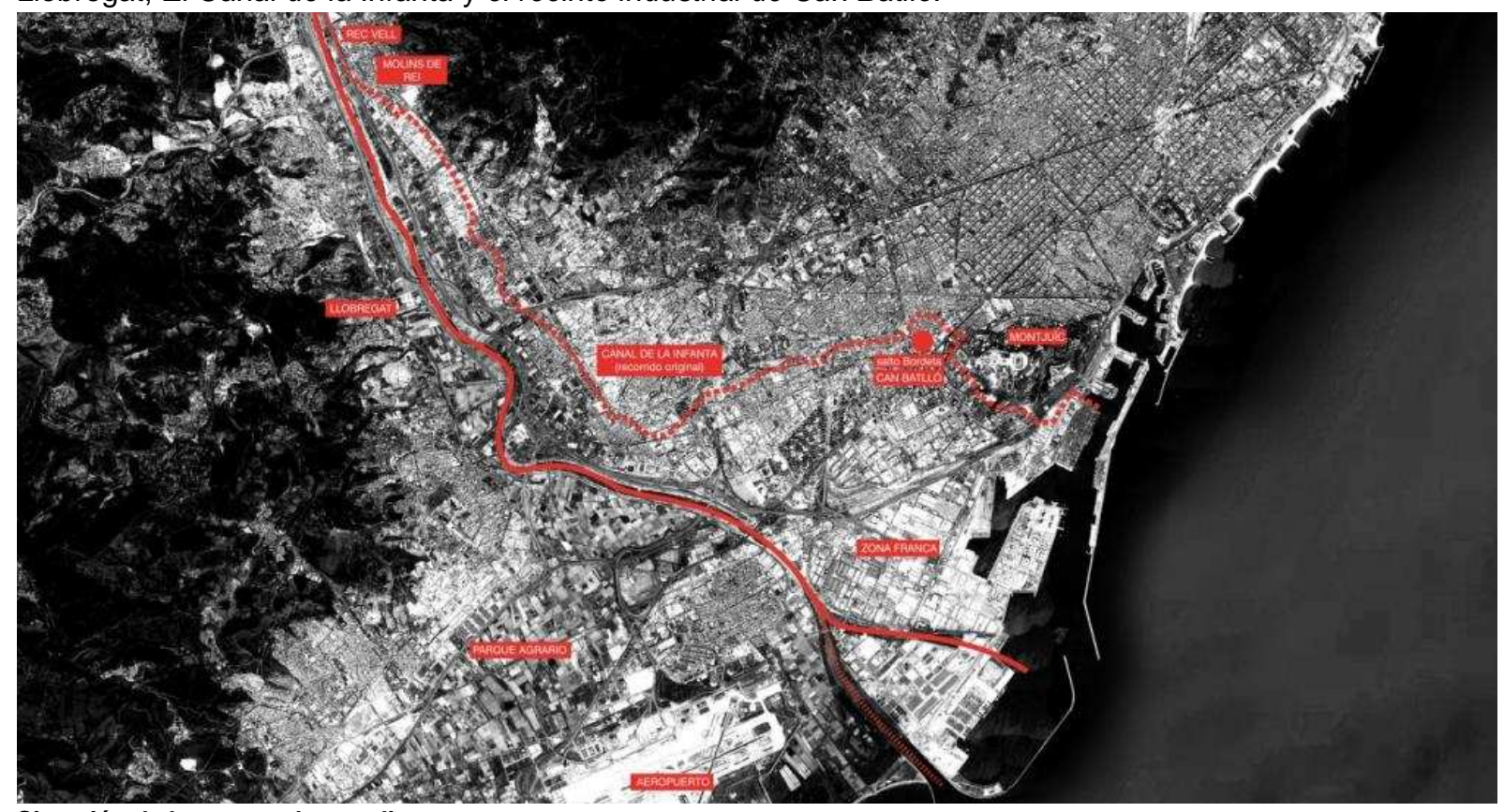

Situación de los casos de estudio

Elaboración propia 


\section{CASO 01: EL CANAL DE LA INFANTA}

\section{De demanda histórica a Infraestructura auto-gestionada ${ }^{13}$}

El Canal de la Infanta es una infraestructura de riego construida a principio del siglo XIX, que jugó un papel primordial en el desarrollo histórico del Baix Llobregat y de Barcelona. Toma el sobrante de las aguas del Llobregat que discurren por el Rec Vell -en Molins de Rei- $y$, tras recorrer 17,42 km por el margen izquierdo del río, desemboca en el Mediterráneo al borde de la montaña de Montjuïc. Tiene una sección rectangular que va de los 2 a los 4 metros de ancho y una profundidad media de 1,5 $\mathrm{m}$. A día de hoy, aunque muy deteriorado, aún fluye agua por algunos tramos.

Antes de su construcción, el margen izquierdo del Baix Llobregat era un área agrícola con la escasa producción propia de los cultivos de secano. Hacía varios siglos que el campesinado reclamaba la construcción de un canal que trajese a sus tierras las aguas del Llobregat. Sin embargo, esto no era posible debido a la oposición histórica de la Corona española, que en aquel entonces tenía el monopolio de la construcción y gestión de todo tipo de canales destinados al riego agrícola. Cuando se construye el Rec Vell, en 1188, ya se prevé su llegada hasta Barcelona. Sin embargo, la complejidad técnica y los problemas de financiación interrumpen su construcción a la altura de Molins de Rei.

A principios del siglo XIX Catalunya se ve afectada por conflictos bélicos con sus consiguientes hambrunas. Ante la presión social por paliar estos problemas, Fernando VII aprueba un Real Decreto (1816) mediante el cual derogaba su autoridad exclusiva sobre los canales de riego. La Corona nunca dispuso de financiación, con lo que son los agricultores del margen izquierdo del Llobregat, que recientemente obtienen beneficios con la introducción de la viña y la mejora en los cultivos de secano, los que llevan a cabo la obra que venían reclamando desde hacía siglos. En su origen, este canal es un claro ejemplo de recurso común coproducido y auto gestionado por la comunidad local.

Entre 1817 y 1820 el campesinado auto-organizado en la Junta del Canal, construye la infraestructura de riego que permite transformar de secano a regadío sus campos de cultivo. La intervención se lleva a cabo sin aporte de capital público y la Junta del Canal se hace cargo de su financiación y gestión. En función de la extensión de sus tierras, cada propietario debía aportar recursos para la financiación de la infraestructura. En un primer momento el canal se denomina Canal de Castaños, en honor al Capitán General de Catalunya, que ayuda a financiar el proyecto con su capital privado.
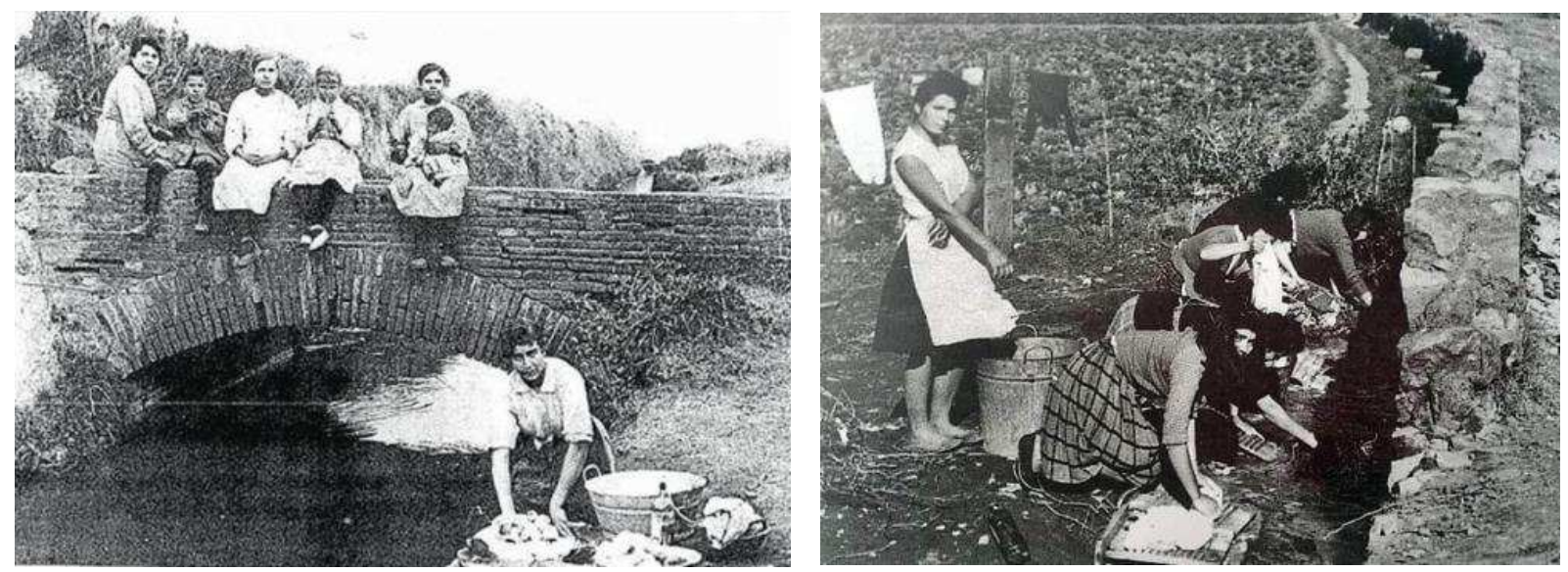

La comunidad y el Canal

Imagen1: 1919 Puig, Joan; Imagen 2: autor y fecha desconocida. Protegim el Canal de la Infanta

\footnotetext{
${ }^{13}$ Los datos utilizados en este apartado han sido obtenidos de la entrevista realizada el 21/04/2017 a Ireneu Castillo, coordinador de la plataforma Protegim el Canal de la Infanta, sus publicaciones (Castillo Caso 2014; Castillo Caso y et al. 2015) y las redes sociales de la plataforma (http://canaldelainfanta.blogspot.com.es/ y https://www.facebook.com/groups/canalinfantalh/)
} 
La deuda contraída por la Junta del Canal, debido a los sobrecostes en la obra, obliga a optimizar los beneficios aprovechando la energía de los saltos de agua en los primeros molinos e industrias (Romeu i Alemany 1991). Esto sienta las bases para la posterior industrialización. Si bien es cierto que parte del sector textil se basa en fábricas con máquinas de vapor o energía eléctrica, éstas se ubican en torno a las industrias preexistentes que dependen de la energía de los saltos de agua.

Probablemente al vislumbrar las expectativas económicas del aprovechamiento de los saltos de agua, en 1824 el Real Patrimonio rectifica el Real Decreto (1816) y se reserva el derecho de "construir artefactos movidos por agua" en el canal. También obliga a la Junta a pedir permiso y pagar los derechos para instalar fábricas y a los terratenientes a pagar por el agua de riego (Romeu i Alemany 1991, p. 133). En el contexto de este conflicto, y como estrategia para paliar las críticas a la infraestructura, la Junta acaba denominándola oficialmente "Real Canal de la Serenísima Infanta Doña Luisa Carlota de Borbón".

\section{Huerta de Europa y esplendor textil}

En 1855, ante el éxito del Canal de la Infanta, se construye una infraestructura similar en el lado derecho del Llobregat ("Canal de la Dreta"). En 1893 se descubre el acuífero profundo en el delta. La conjunción de los canales y los nuevos pozos artesianos incrementan la productividad y en consecuencia el comercio. En unos años la producción del Baix Llobregat pasa del comercio local, al comarcal y, poco después, a la exportación a Europa. El ámbito llega a conocerse como "La Huerta de Europa".

El esplendor agrícola y la rápida industrialización del ámbito, la cercanía a Barcelona, y el éxito de las Exposiciones Universales de 1888 y 1929, atraen a la zona nuevos habitantes que buscan oportunidades de trabajo. En el primer tercio del siglo XX todo el ámbito comienza a experimentar un gran desarrollo urbano.

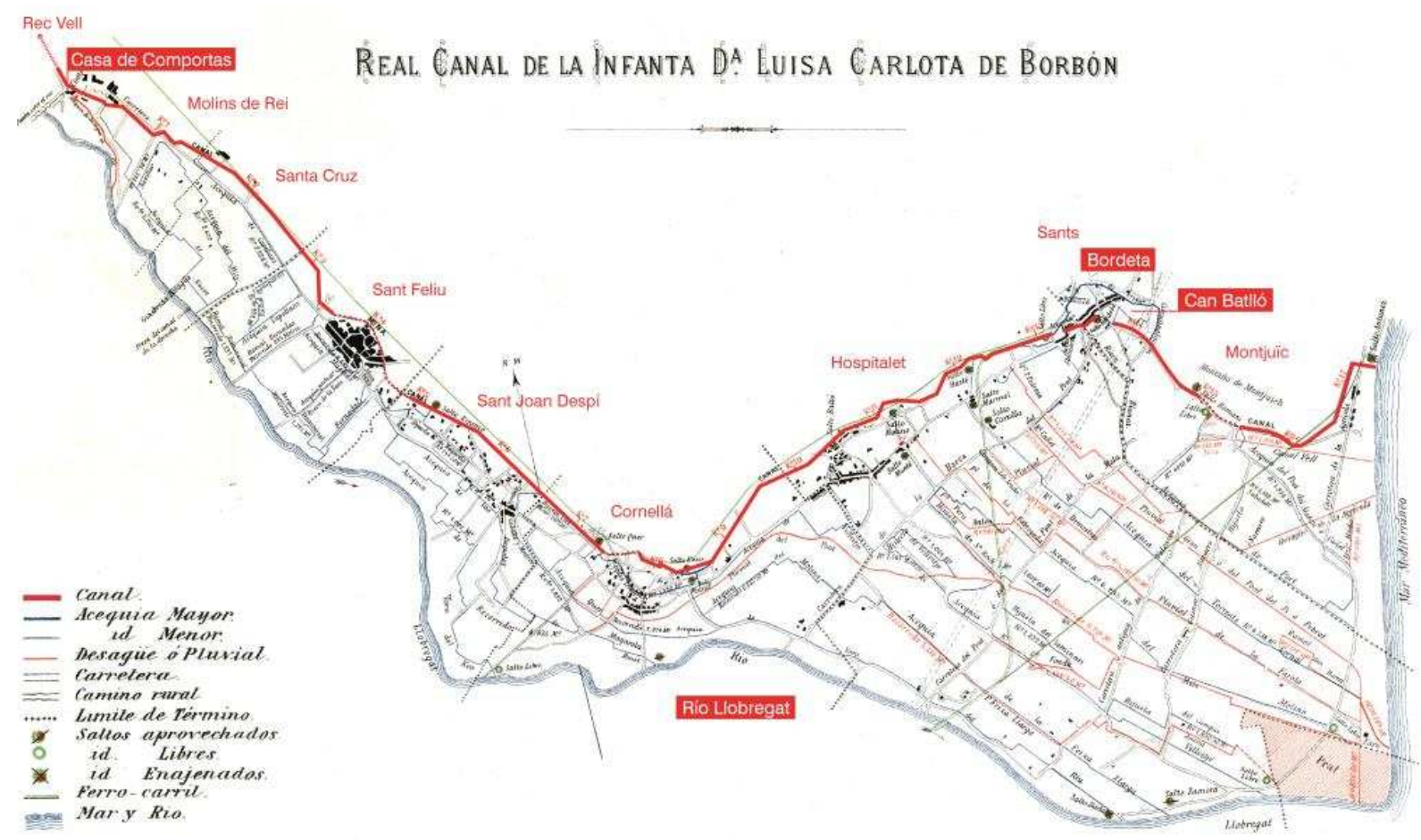

\section{El Canal de la Infanta en 1908}

Anotaciones sobre el plano de Mariano Tomás y Barba. ICGC

\section{De infraestructura olvidada a problema de salubridad pública}

La Guerra Civil y el comienzo del franquismo traen consigo la autarquía económica. El comercio del ámbito vuelve a ser local y se reducen al mínimo las exportaciones. A pesar de esto, la situación del resto del estado es todavía peor. Las tierras que riega el canal continúan siendo el destino de nueva vivienda para 
acoger las oleadas migratorias. El rápido incremento poblacional implica la substitución de la comunidad local y la pérdida de los vínculos emocionales y recuerdos asociados al canal. La presión urbana, sumada al empeoramiento económico por las dificultades de exportación complica cada vez más la agricultura.

A mediados del siglo XX la extensión de la urbanización absorbe varios tramos del canal. La falta de un planeamiento adecuado hace que pronto surjan problemas hidráulicos y de saneamiento que afectan seriamente a la centenaria infraestructura. La red de saneamiento se ve superada por el crecimiento de la población y el canal acaba recibiendo parte de los vertidos incontrolados. Otro duro golpe para el canal es la creación de la Zona Franca y la inauguración de la Fábrica Seat en 1955.

El empeoramiento de la calidad del agua y la transformación de parte del ámbito en zona industrial, ya sin vínculo con la tradición agrícola del lugar, hace que decrezca la producción agraria. Además, la presión urbana y el aumento del valor del suelo dificultan el mantenimiento de los cultivos. Poco a poco éstos van decreciendo y el canal cae en el olvido.

A pesar de que en el año 1955 se construye la depuradora de Sant Joan Despí, los problemas de abastecimiento de Barcelona continúan creciendo y las aguas que trae el Llobregat cada vez llegan más contaminadas. Los estudios realizados por la "Sociedad General de Aguas de Barcelona" llegan a la conclusión de que desviar las aguas superficiales de la riera de Rubí i del río Anoia -las más contaminadas-, hacia el sistema del Canal de la Infanta, podría ser un parche temporal que aliviase la carga de trabajo de la depuradora. A pesar de la oposición inicial de la Junta del Canal, en 1968 se lleva a cabo el desvío, en principio provisional, de los caudales contaminados. Esto supone que los campos que aún se regaban con las aguas del canal, pasen a regarse con aguas residuales.

La solución provisional acaba siendo definitiva y se provocan depósitos de sedimentos que deterioran muchos tramos de la infraestructura. Sin embargo, la peor consecuencia es el desprestigio que implica el flujo de aguas residuales a cielo abierto. A partir de ese momento la población empieza a asociar el Canal de la Infanta con un problema de insalubridad pública. En menos de una década, son los propios movimientos vecinales los que reclaman que se entierren algunos tramos.

Con la muerte del dictador y la llegada de los primeros ayuntamientos democráticos, el Canal de la Infanta es expropiado y pasa a depender de los ayuntamientos que atraviesa, que tratan de solucionar parcialmente los problemas específicos de cada tramo. Aunque la Junta del Canal continúa siendo la encargada de gestionar los derechos de riego de los agricultores, la pérdida de la propiedad reduce drásticamente su capacidad para garantizar el mantenimiento en todo el recorrido.

\section{"Protegim el Canal de La Infanta!"}

Con el paso de los años, los tramos de la infraestructura que continúan descubiertos conviven con la trama urbana y forman parte de la cotidianidad de la ciudadanía. Por iniciativa de algunos agentes interesados en el patrimonio, surge en el 2011 en L'Hospitalet la plataforma vecinal "Protegim el Canal de la Infanta!". A la misma se adhieren varios individuos y asociaciones que hasta ese momento reivindicaban el Canal localmente. El potencial de esta iniciativa radica en su capacidad articuladora de las distintas reivindicaciones ${ }^{14}$ ya que entiende el canal en su globalidad.

La labor de la Plataforma se ve recompensada en 2012 con la aprobación en el Parlamento de Catalunya de la iniciativa para estudiar su declaración como Bien Cultural de Interés Nacional. Sin embargo la Dirección General de Patrimonio no aprueba la declaración al considerar que la infraestructura ya está demasiado fragmentada y degradada, aunque insta a los ayuntamientos a musealizarlo y protegerlo a nivel local.

\footnotetext{
${ }^{14}$ En el blog de la plataforma (http://canaldelainfanta.blogspot.com.es/) se pueden ver las asociaciones adheridas.
} 
En cada uno de los ayuntamientos la relación de la administración pública y el sector privado con la infraestructura es muy diferente. En Molins de Rei, la Casa de Comportas es incluida en el Inventario del Patrimonio Arquitectónico Catalán. En Cornellá se comprometen a poner en valor el tramo del canal de Can Mercader a L'Hospitalet. En otros casos el desarrollo urbanístico, aún a día de hoy amenaza su integridad. Un ejemplo de esta situación es el Área Residencial Estratégica (ARE) en el antiguo Cuartel de la Remunta (Hospitalet). El proyecto inicial de reparcelación para desarrollar el ámbito ignora por completo el canal y se superpone a uno de los tramos aún conservados. La presión de la Plataforma consigue que se modifique el proyecto de reparcelación y el viario, pasando la avenida Josep Tarradellas de cuatro a dos carriles (Cabañas 2012). La movilización popular consigue salvar un puente que cruzaba la infraestructura y que se pavimente de forma singular parte del trazado. Sin embargo, el resultado final dista mucho de ser una intervención ejemplar en la revalorización patrimonial.

Actualmente algunas acequias de la infraestructura continúan siendo utilizadas por agricultores. Otros tramos del canal están soterrados bajo el viario o están integrados en la red de saneamiento público.

\section{CASO 02: RECINTO INDUSTRIAL DE CAN BATLLÓ De Can Mangala a Can Batlló}

A principios del siglo XIX, el barrio de La Bordeta, por el que transcurre el trazado del Canal de la Infanta, está formado por pequeñas viviendas, bordas, masías y huertos estructurados entorno a la actual calle Bordeta, Gava, Constitución-. Gracias al canal, a lo largo del siglo proliferan en el barrio actividades industriales de distintas características: Molino de la Bordeta, alimentaria; Talleres de la Hispano Suissa, automovilística; o la La Pellería Gatius, peletera (Gawron y Vidal Moranta 2012, p. 42). En este proceso de industrialización los agricultores devienen obreros de forma progresiva.

En 1878 el Ingeniero J. A. Molinero firma el proyecto de la fábrica Can Batlló, en lo que hasta ese momento eran los fértiles campos de Can Mangala, muy próximos a uno de los saltos de agua del Canal de la Infanta. La fábrica entra en funcionamiento en 1880. El galardón obtenido en la Exposición Universal de 1888, por "la perfecció i baratura dels seus teixits blancs" (Cabana 1992), es una prueba del esplendor que pronto experimenta.

Dada la extensión del recinto y la importancia económico-social de la actividad textil, el crecimiento urbano y demográfico del barrio se desarrolla estrechamente vinculado a la evolución de la fábrica, que pronto se convierte en un símbolo del movimiento obrero.

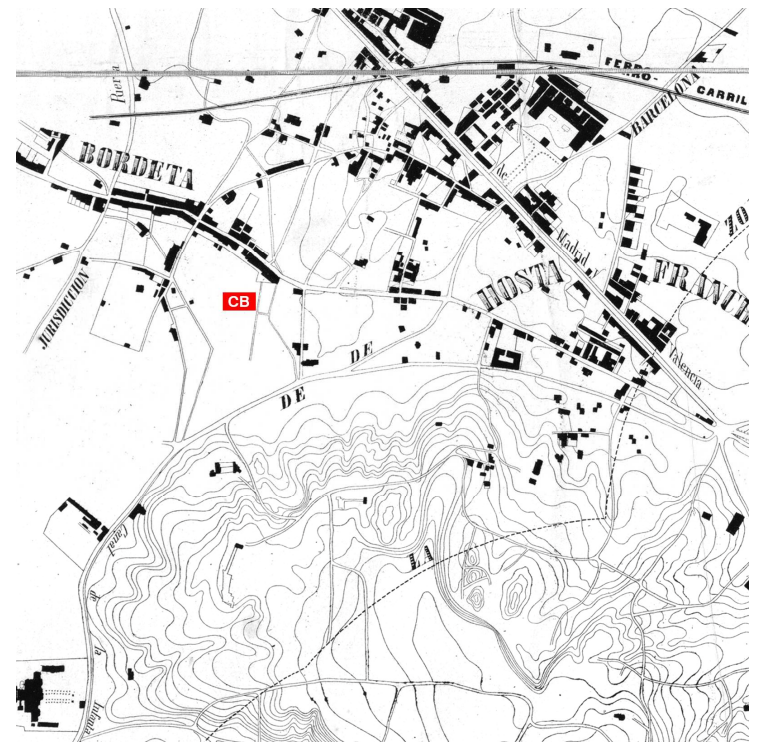

La Bordeta en 1855

Fragmento del plano de los alrededores de Barcelona, Ildefonso Cerdà. ICGC.

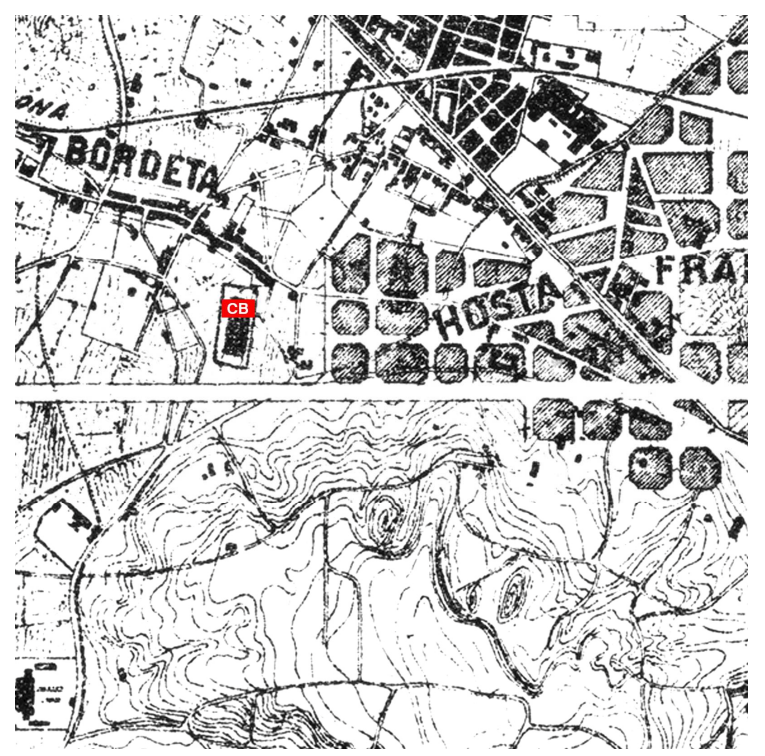

La Bordeta en 1888

Fragmento plano general de Barcelona y sus alrededores, Leopoldo Rovira y Deloup. ICGC. 
Durante la Guerra Civil, la familia Batlló se exilia, y los trabajadores colectivizan la fábrica, llegando a aumentar su producción. Este período queda truncado con el regreso de los Batlló al final de la guerra y el principio de la dictadura (Castro-Coma et al. 2011).

\section{Franquismo, desarrollismo y movimientos vecinales}

Durante el franquismo, la fábrica es adquirida por Julio Muñoz Ramonet -un financiero enriquecido gracias a sus vínculos con la dictadura (Muñoz 2003). En el declive del sector textil, su nuevo dueño transforma el recinto en un complejo de empresas y talleres artesanales (Castro-Coma et al. 2011). La popular frase en el vecindario de La Bordeta: "En el cielo manda Dios y en La Bordeta los Muñoz" (La Col 2013, p. 39), da fe de la importancia que los nuevos propietarios llegan a tener en el barrio.

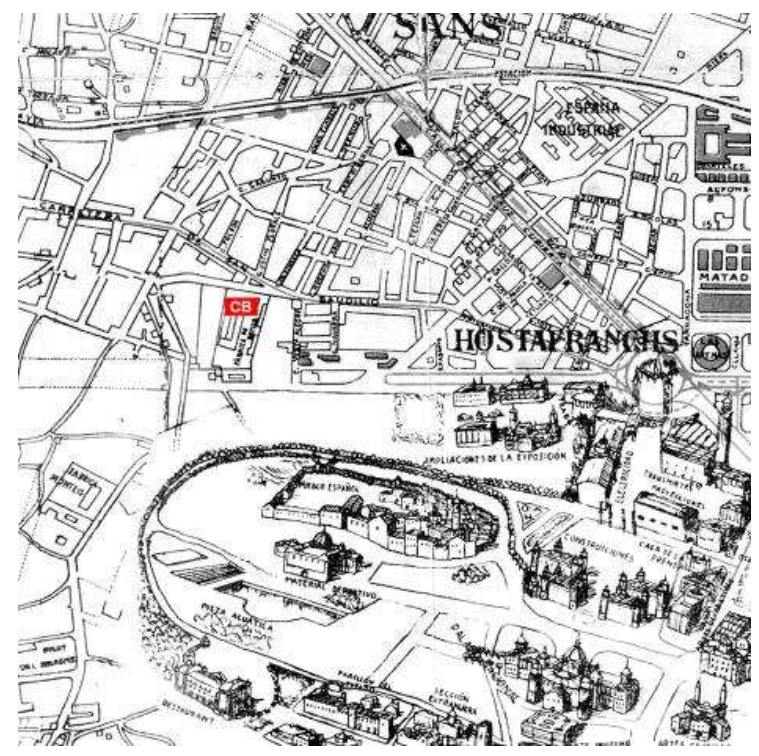

La Bordeta en 1929

Fragmento del plano de Barcelona y sus alredores, Gráficas Bobes, S.A., sociedad de publicaciones. ICGC.

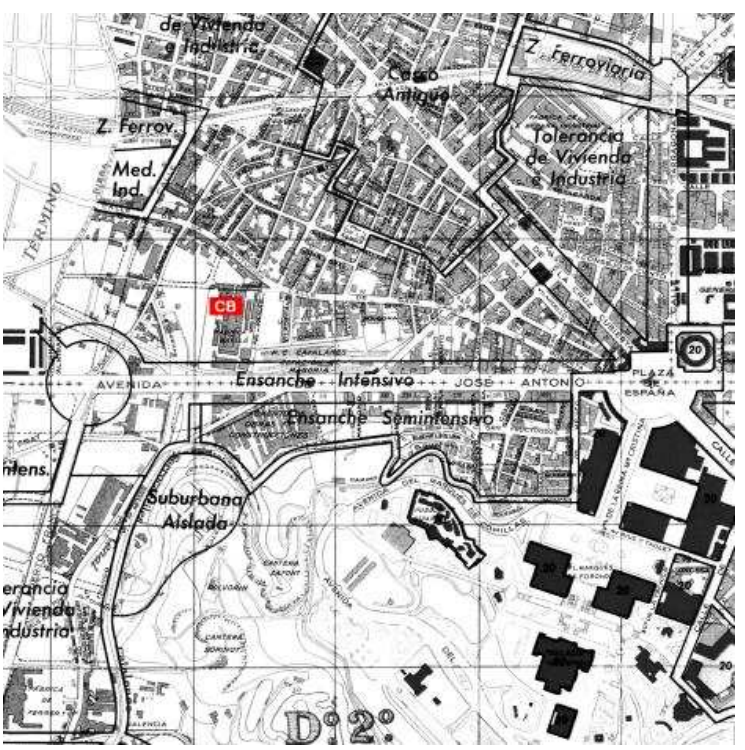

La Bordeta en 1953

Fragmento del plano de Zonas del Plan de Ordenación de Barcelona. Ajuntament de Barcelona. ICGC.

El Plan Comarcal de 1953 supone la apertura de la Ronda del Mig y la construcción de nuevos bloques que implican derribos de pequeñas viviendas. El tejido residencial del barrio se densifica progresivamente, generando una importante carencia de espacios libres, zonas verdes y equipamientos. En esa época se amplía la fábrica.

Este contexto se caracteriza por el auge y empoderamiento de movimientos vecinales, que empiezan a tomar consciencia y reivindicar su derecho a la ciudad. La apertura de la Parroquia de Sant Medir (1948), a escasos metros del recinto, marca un hito muy importante en el asociacionismo vecinal. La actividad política de la parroquia supera muchas veces lo religioso -en ella se lleva a cabo la primera asamblea del sindicato CC.OO. en 1965-. Otro momento importante en los movimientos sociales del barrio es la creación en 1971 del Centro Social de Sants, que aún a día de hoy juega un papel fundamental como aglutinador movilizaciones vecinales y las reivindicaciones de Can Batlló ${ }^{15}$.

\footnotetext{
${ }^{15}$ En la campaña y exposición fotográfica Cop d'ull a Sants (1973) se recogen las primeras reivindicaciones sobre Can Batlló: "O recuperamos los grandes espacios libres que aún no han sido edificados que quedan en el barrio (como son la España Industrial, Can Batlló, Estación de Magoria), o dentro de pocos años nos veremos abocados a un colapso sin salida..."
} 


\section{Barbecho de Can Batlló}

El barrio de La Bordeta fue un gran olvidado en las operaciones de mejora del período de éxito del urbanismo barcelonés durante los primeros Ayuntamientos democráticos. Además, la voluntad de expulsar la industria de la ciudad, materializada en el Plan General Metropolitano de 1976, hace que el tejido industrial de Can Batlló quede obsoleto y en espera de substitución. En el año 1997 la antigua estación de La Magòria también queda en desuso. Desde ese momento, el ámbito formado por el recinto fabril y la estación conforma una gran bolsa de suelo en barbecho, a la espera de un desarrollo inmobiliario suficientemente rentable.

Ayuntamiento y propiedad (gran parte del recinto pertenece al Grupo Gaudir, entidad inmobiliaria de la familia Muñoz) promueven diferentes modificaciones del plan metropolitano, con un progresivo aumento del número de viviendas. Este incremento de la edificabilidad residencial, junto con la revalorización del ámbito, derivada de la nueva centralidad del Eje Gran Vía-Hospitalet, genera nuevas expectativas de negocio.

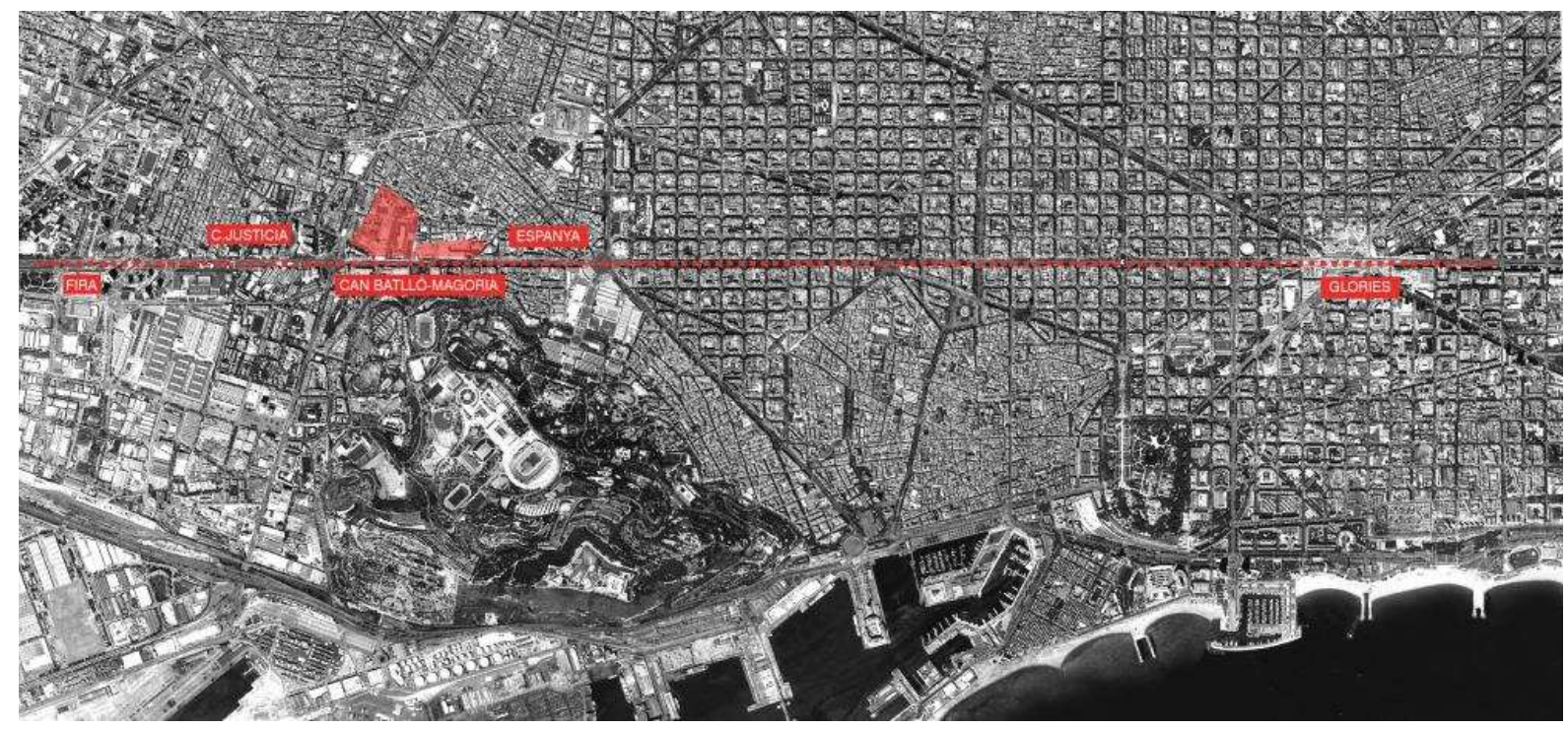

En 2006 se aprueba la MPGM que contempla la construcción de más de 1.600 viviendas. Sin embargo, el acuerdo llega demasiado tarde y la crisis del sector inmobiliario hace que el proyecto no se lleve a cabo.

La falta de equipamientos y zonas verdes es un problema histórico del barrio, uno de los más maltratados por el proceso urbanístico, al margen de las mejoras en otras zonas de la ciudad.

\section{"Can Batlló es pel Barri"}

En 2009 se reactivan las reivindicaciones históricas sobre el recinto fabril, formándose la Plataforma Can Batlló es pel Barri. Poco después, se pone en marcha la estrategia denominada: "Tic Tac Can Batlló", que plantea un ultimátum: si no se empiezan las obras de urbanización del recinto, serán los propios vecinos los que tomarán la iniciativa ("iSi no lo hacéis vosotros lo hacemos nosotros!”).

En 2011, después de varias décadas de reivindicaciones, la comunidad de la Bordeta se cansa de esperar los equipamientos que les han prometido y ocupan ${ }^{16}$ el recinto de Can Batlló. A partir de ese momento, transforman el Bloque 11 en un equipamiento comunitario auto-gestionado.

A pesar de que es indudable el valor simbólico del recinto como aglutinador de identidad, en un primer momento no está, entre las prioridades de la mayoría del vecindario, la de preservar dicho patrimonio. La percepción general, tanto de la sociedad civil, como de la administración pública y la propiedad, es la de un espacio susceptible de ser urbanizado y ocupado con nuevos usos. Buena prueba de ello es el PGM del

\footnotetext{
${ }^{16}$ Unos días antes del final del plazo planteado por los vecinos, la propiedad, a través de un convenio con el ayuntamiento, cede el recinto para evitar que sea okupado de forma ilegal. (La Col 2013, p. 100-101)
} 
1976, que con cierta influencia del vecindario, califica el ámbito del recinto como zona verde y de equipamientos ${ }^{17}$. Esto firma la sentencia del ya muy decadente sector industrial. La MPGM del 2006 expresa la voluntad de preservar el recuerdo de la estructura industrial del recinto. Sin embargo solo mantiene los elementos catalogados por el Plan Especial de Patrimonio de Sants-Montjuïc: la nave principal, la chimenea grande, la torre del depósito de agua y parte del muro de cierre en el lado de la Gran Vía. (Navarro 2015)

\section{Un Patrimonio, tres relatos}

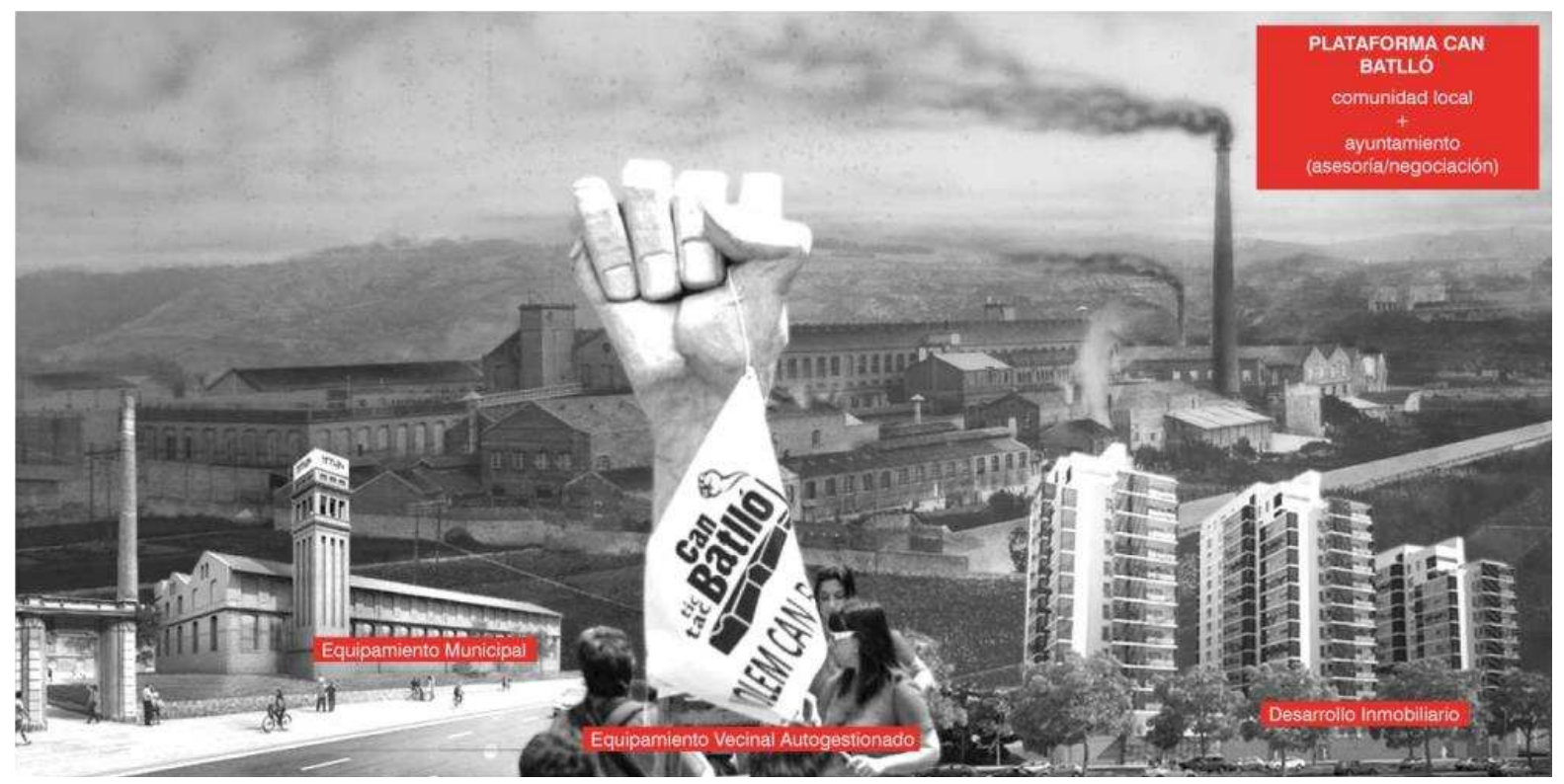

Can Batlló: Un patrimonio, tres relatos

Collage de elaboración propia a partir de Imagen 1: Can Batlló en 1890, fuente desconocida; Imagen 2: nueva sede EMAV, Ayuntamiento de Barcelona; Imagen 3: Plataforma Can Batlló; Imagen 4: Batlle i Roig

Actualmente en el ámbito formado por el recinto industrial de Can Batlló y el sector de La Magoria (casi 14 ha) confluyen tres relatos con distintas perspectivas de utilización:

- La comunidad local, organizada de forma asamblearia en la Plataforma de Can Batlló, programa actividades en varias naves del antiguo recinto textil. Agrupados por comisiones, cooperan para construir un equipamiento comunitario que consta de una biblioteca -de aproximadamente $300 \mathrm{~m}^{2}$ con más de 10.000 volúmenes procedentes de donaciones-; un bar -espacio de encuentro donde se organizan actuaciones de pequeño formato-; un auditorio -espacio polivalente preparado acústicamente y climatizado, con capacidad para 400 personas-; un centro de documentación -de los movimientos sociales en el que participa la cooperativa La Ciutat Invisible-; un rocódromo; varios talleres -carpintería, infraestructuras, cerveza, movilidad, imprenta...-; La Borda -una cooperativa de vivienda en cesión de uso que se está construyendo en uno de los solares de la calle Constitución-; Coópolis -un vivero de cooperativas de economía social previsto en los $4.000 \mathrm{~m}^{2}$ de una de las naves vacantes-; y Arcadia -una escuela alternativa-. (Alguacil 2015; Plataforma Can Batlló 2009; La Col 2013)

- Para la Inmobiliaria Gaudir, propietaria de parte del recinto, Can Batlló es un solar susceptible de desarrollo urbano. La propuesta de MPGM, que los vecinos aceptan a cambio de los equipamientos y zonas verdes que llevan tiempo reclamando, queda encallada por la llegada de la crisis. Se prevé la construcción de 1.656 viviendas -de las cuales 985 libres, 471 protegidas y 200 dotacionales- (Navarro 2015). Este relato se complementa con un intento de rescate público, denominado Plan Empenta, que

\footnotetext{
${ }^{17}$ A pesar de que los Planes Populares previos al PGM contemplaban la compatibilidad entre recuperación del patrimonio industrial y la necesidad de nuevos equipamientos.(Magro Huertas y Montaner 2014, p. 278)
} 
pretende desencallar el desarrollo urbanístico del recinto mediante el pago con dinero público de parte de las indemnizaciones y expropiaciones pendientes (S. Baquero 2012; Europa Press 2012).

- Por parte de la administración pública, en 2006 se inaugura un Casal Civic en la antigua estación de la Magoria. Además la MPGM prevé la construcción de varias zonas verdes y 21 equipamientos (un IES, un CEIP, una escuela, un espacio cívico, una residencia de la tercera edad, varios equipamientos deportivos, una biblioteca de barrio y salas de exposiciones, un centro ocupacional y un CAP).

En el año 2014 se inaugura el CAP Bordeta-Magoria y se urbaniza una de las calles del recinto y algunos ejes verdes del futuro parque. En el año 2015, el Ayuntamiento presenta el proyecto de rehabilitación de las naves del bloque 7, para acoger la nueva sede de la Escuela de Medios Audiovisuales de Barcelona (EMAV). El dossier de prensa prevé su inauguración en septiembre de 2017 (Ajuntament de Barcelona 2015).

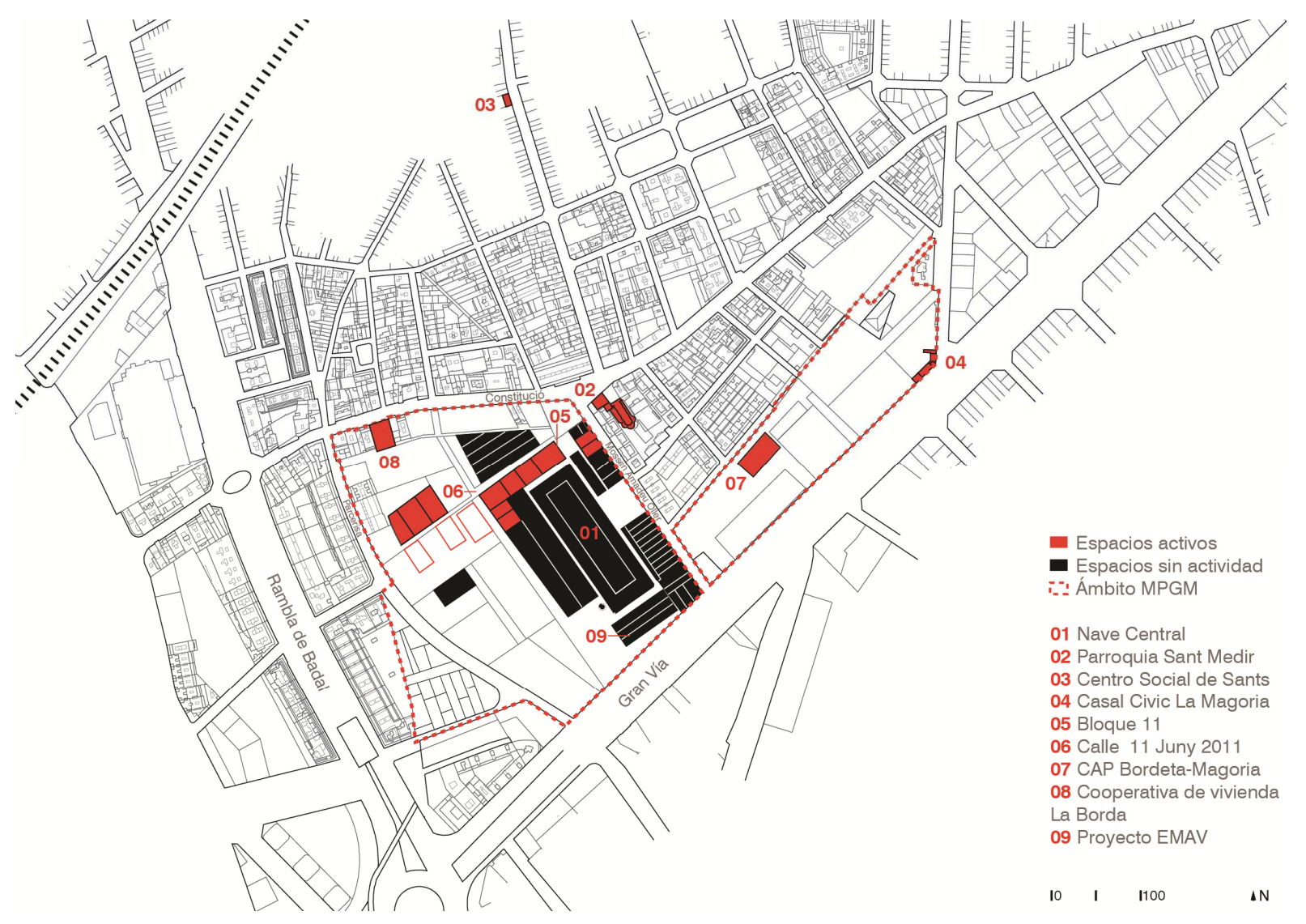

Can Batlló La Magoria y La Bordeta

Elaboración propia

\section{CONCLUSIONES Y DISCUSIÓN}

Después de este recorrido se confirma la importancia del papel que juega la comunidad local en la construcción del paisaje y en la conservación del patrimonio heredado. Sin embargo, el valor que cada comunidad atribuye a los paisajes productivos evoluciona en función de aspectos históricos económicos, sociales y culturales.

En su origen, el Canal de la Infanta es un bien común construido y auto gestionado por sus usuarios. A pesar de las trabas que encuentra en su construcción y las dificultades a lo largo de la historia, la 
infraestructura se mantiene a pleno rendimiento durante más de un siglo. La carencia de un planeamiento que regule de forma adecuada el crecimiento de la ciudad, durante la época del desarrollismo, genera una serie de patologías que se plasman en el estado actual del canal.

En el caso de Can Batlló, es una élite económica minoritaria la que construye el recinto, aprovechando las sinergias generadas por el Canal de la Infanta y las infraestructuras que surgen próximas a su emplazamiento. Sin embargo, el valor cultural de la fábrica se le debe atribuir a los obreros que tejen el espíritu de comunidad en torno al recinto. Es también el esfuerzo acumulado de los trabajadores y trabajadoras la causa del esplendor de la fábrica y su expansión. Lo construido es el resultado de un proceso cooperativo. No hay que olvidar que el modernismo barcelonés, tan promovido para atraer visitantes, no sería posible sin toda la red de fábricas que cada día ponían en funcionamiento miles de obreros. El caso de la fábrica de Can Batlló y la Casa Batlló da buena muestra de esta estrecha relación. Cabe aquí recordar las discusiones iniciales en las que se planteaba la pregunta de ¿Quién decide que se debe preservar? ¿Cuáles son los valores que se quieren transmitir a generaciones venideras a través del patrimonio?

Se puede concluir que tanto en el Canal de la Infanta, como en Can Batlló, la relación de la comunidad con el patrimonio pasa por cuatro fases fácilmente asimilables:

\section{- Origen:}

Canal y fábrica son resultado de una determinada necesidad productiva. Los regantes de una zona sin agua necesitan traerla del río más próximo. La familia de industriales, que huye de un entorno más urbano ${ }^{18}$, construye la fábrica -el ejemplo más literal de morfología productiva- en las proximidades del canal para aprovechar las sinergias industrializadoras del ámbito.

\section{- Auge:}

Poco después de su origen experimentan un auge productivo, económico y social que los convierte en catalizadores de un proceso identitario compartido. El canal posibilita el cambio del sistema agrícola de secano a regadío e inicia la industrialización. Entre tanto, la comunidad, en su ámbito directo de influencia, teje historias en torno a la infraestructura. La gente se baña en el canal, lava la ropa en el canal, pasea en torno al canal... La fábrica configura la forma urbana del barrio de La Bordeta, aglutina los movimientos obreros y vecinales antifranquistas, posibilita el esplendor del modernismo barcelonés,...

\section{- Declive:}

Los cambios en el sistema económico debilitan el sentido productivo del canal y de la fábrica. Esta ruptura trae consigo el olvido de su razón de ser, su deterioro y los convierte en una molestia para una sociedad en busca de mejoras. En el caso del canal, este declive se traduce en un problema de insalubridad pública que lo desprestigia socialmente. Además, la substitución de la población en su ámbito hace que se pierda la memoria histórica. El único motivo que imposibilita su eliminación completa es que aún resulta imprescindible para el maltrecho sistema hidráulico. En el caso de la fábrica, el desprestigio y prohibición de la industria en la ciudad lo convierte en un espacio obsoleto dentro de un barrio con demanda de zonas verdes y equipamientos.

\section{- Reivindicación:}

El valor simbólico latente en el período de declive se reactiva cuando un determinado colectivo aglutina sus intereses en torno al patrimonio. No siempre es un acto en el que prime el valor patrimonial del vestigio. En el caso del Canal de la Infanta, los colectivos que lo reivindican valoran la memoria histórica y valor patrimonial que atesora una infraestructura clave en la historia de Catalunya. Sin embargo, en el caso del recinto fabril, el valor del patrimonio reside más bien en su capacidad simbólica de aglutinar intereses compartidos en torno a la memoria del barrio y la oportunidad que representa un espacio versátil y sin uso.

\footnotetext{
${ }^{18}$ El primer emplazamiento de Can Batlló fue en Compte d’Urgell, en el Ensanche. Debido a los conflictos obreros en aquel emplazamiento, parte de la familia decide abrir otra fábrica Can Batlló en la Bordeta. Quizás influyó en la decisión la expectativa de encontrar entre el campesinado, aún sin politizar, mano de obra más dócil.
} 
En ninguno de los dos casos se puede hablar aún de un proceso de revalorización culminado. El canal, aunque sigue parcialmente en uso, está muy deteriorado y los esfuerzos de la plataforma y asociaciones que lo reivindican aún no cuentan con el apoyo institucional que garantice su puesta en valor. En la fábrica, el proceso está mucho más avanzado y la reactivación de algunas de las naves ha hecho que parte de los actores implicados se sensibilicen en torno a su valor patrimonial. En ambos casos hará falta más tiempo para descubrir si el proceso de recuperación puesto en marcha con la reivindicación culmina con éxito.

La lectura de estos ámbitos patrimoniales desde la perspectiva de los paisajes culturales, nos permite aproximarnos a las causas de las patologías identificadas. El deterioro del Canal de la Infanta es el reflejo de un problema en la relación de una sociedad con el agua; ocasionado por el rápido crecimiento urbano sin adecuada planificación durante el franquismo. En el Caso de Can Batlló, una política urbanística equivocada, que expulsa la actividad industrial de la ciudad, deja sin capacidad productiva una infraestructura aún activa. La pérdida de la vocación sumada a las perversiones de la burbuja inmobiliaria da lugar al proceso de degradación patrimonial. Ambos son el resultado de la cooperación y competencia de los distintos agentes involucrados en la construcción del paisaje. Juntos ensanchan el ámbito de influencia productivo del río Llobregat. Las alianzas de actores en cada período determinan qué permanece y qué se elimina. Al fin y al cabo el patrimonio es el palimpsesto que refleja las cosmovisiones hegemónicas de cada época.

Probablemente en la memoria de estos paisajes productivos se encuentren las claves para su futuro. La metáfora de la Khôra de los Comunes nos permite imaginar de nuevo el Llobregat como el recurso común que articula territorialmente las voluntades de las comunidades locales que lo habitan. 


\section{BIBLIOGRAFIA}

AJUNTAMENT DE BARCELONA, 2015. Can Batlló acollirà la nova seu de I 'Escola de Mitjans Audiovisuals (EMAV). Dossier de Premsa,

ALGUACIL, F., 2015. Can Batlló Feature. Bcnmes,

BOHIGAS, O., 2005. El model Barcelona, segons Horacio Capel. Avui, pp. 21.

CABANA, F., 1992. Fabricants i empresaris. Els protagonistes de la revolució industrial a Catalunya. Barcelona: Enciclopèdia Catalana. Vol 2.

CABAÑAS, N., 2012. TRANSFORMACIÓ URBANA DE LA CASERNA DE LA REMUNTA. Observatori de projectes i debats territorials de Catalunya,

CAPEL, H., 2006. De nuevo el modelo Barcelona en el debate sobre el urbanismo barcelonés. Biblio $3 W$ REVISTA BIBLIOGRÁFICA DE GEOGRAFÍA Y CIENCIAS SOCIALES, vol. Vol. XI, n, no. Serie documental de Geo Crítica.

CASTILLO CASO, I., 2014. El Canal de la Infanta: quan la importància històrica esdevé una amnèsia èpica. Quaderns d'estudi, vol. Núm. 27, no. El patrimoni de I’Hospitalet, pp. 61-84.

CASTILLO CASO, I. y ET AL., 2015. El Canal de la Infanta. La recuperació d’un patrimoni. S.I.: L'Aven\}. ISBN 978-84-606-9250-8.

CASTRO-COMA, M., MARTÍ-COSTA, M., GUAL, J. y MARTÍNEZ MORENO, R., 2011. Can Batlló: Construir comunidades en las ruinas de la crisis. 2011. Madrid: s.n.

DE SOLÁ-MORALES, M., 1992. Espacios públicos y espacios çolectivos. La Vanguardia, Cultura y Arte.

DERRIDA, J., 1993. Khôra. París: Galilée. ISBN 9782718607306.

EUROPA PRESS, 2012. El Ayuntamiento invertirá 10 millones para desencallar la transformación de Can Batlló. Europa Press,

FERNÁNDEZ AGIS, D., 2009. Cuerpo, Khôra y espacio político. Eikasia. Revista de Filosofía, vol. 29, no. Noviembre 2009, pp. 23-30.

GAWRON, A. y VIDAL MORANTA, B. (tutor), 2012. El Modelo Barcelona de Espacio Público y diseño urbano. Fabrica de Can Batlló y el proceso de su recuperación ciudadana. S.I.: UB. Facultat de Belles Arts.

HARDIN, G., 1968. La tragedia de los comunes. Science, vol. 162, no. 1968, pp. 1243-1248. ISSN 00368075. DOI 10.1126/science.162.3859.1243.

HARDT, M. y NEGRI, A., 2009. Commonwealth. El proyecto de una revolución del común. Akal. Madrid: Akal. ISBN 978-84-460-3230-4.

HARVEY, D., 2013. Ciudades rebeldes: del derecho de la ciudad a la revolución urbana. S.I.: Akal. ISBN 9788446037996.

HESS, C., 2008. «Mapping New Commons.» Presented at The Twelfth Biennial Conference of the International Association for the Study of the Commons, Cheltenham, UK. Syracuse University: SURFACE, pp. 14-18. ISSN 1556-5068. DOI 10.2139/ssrn.1356835.

KRATZWALD, B., 2015. Urban commons - Dissident Practices in Emancipatory Spaces. en Urban Commons: Moving Beyund State and Market, pp. 26-41.

LA COL, 2013. Inventari de Can Batlló: teixint una història col-lectiva. Barcelona: Riera de Magória. ISBN 978-84-616-8186-0.

LEFEBVRE, H., 1968. El derecho a la ciudad. S.I.: Península. ISBN 8429709169. 
MAGRO HUERTAS, T. y MONTANER, J.M. (director), 2014. Hacia la ciudad inclusiva. Prácticas sociales urbanas en Barcelona 1969-1979. S.I.: s.n.

MARTORELL, J., 2005. Fora muralles. Avui, pp. 18.

MARX, K., 1867. El Capital. Tomo1/Vol.1. Libro Primero. El proceso de Producción del Capital. Crítica de la economía política. Siglo XXI. S.I.: s.n. ISBN 978-84-323-0193-3.

MIDNIGHT NOTES COLLECTIVE, 1990. Introduction to then new enclosures. 1990. S.I.: s.n.

MUÑOZ, X., 2003. Muñoz-Ramonet, societat il-limitada. Barcelona: Edicions 62.

NAVARRO, I., 2015. Transformació urbana de Can Batlló. Territori Observatori de projectes i debats territorials de Catalunya [en línea]. Disponible en: http://territori.scot.cat/cat/notices/2016/12/transformaciO_urbana_de_can_batllO_barcelona_3341.php\#

OMA, 2003. Beijing Preservation. [en línea]. [Consulta: 9 enero 2017]. Disponible en: http://oma.eu/projects/beijing-preservation.

OMA, 2010. Venice Biennale 2010: Cronocaos. [en línea]. [Consulta: 9 enero 2017]. Disponible en: http://oma.eu/projects/venice-biennale-2010-cronocaos.

OSTROM, E., 1990. El gobierno de los bienes comunes. La evolucion de las instituciones de accion colectiva. México D.F.: FCE. ISBN 978607-16-0617-4.

PLATAFORMA CAN BATLLÓ, 2009. Can Batlló.org. [en línea]. [Consulta: 11 enero 2017]. Disponible en: https://www.canbatllo.org/agenda/.

PLATÓN, 360 a.C aprox. Timeo. Edición Electrónica de Escuela de Filosofía Universidad ARCIS.

ROMEU I ALEMANY, A., 1991. El Canal de la Infanta i les primeres indústries a L'Hospitalet. 1es Jornades d’Arquetología Industrial de Catalunya, pp. 132-138.

S.BAQUERO, C., 2012. Barcelona desencalla la transformación de la antigua fábrica textil de Can Batlló. El País,

SABATÉ BEL, J., 2005. De la preservación del patrimonio a la ordenación del paisaje. Revista Identidades. Territorio, Cultura, Patrimonio., vol. 1, pp. 15-33.

SABATÉ BEL, J., 2007. Paisajes culturales y desarrollo local: ¿Alta costura o prêt a porter? Revista Labor \& Engenho, no. v.1, n.1, pp. 51-76.

SABATÉ BEL, J., SHUSTER, J.M., BEN-JOSSEPH, E., FRENCHMAN, D., CALATAYUD, D., GALINDO, J., VALL, P., GIOCOLO, A., APIGIAN, M., LISTA, A., DZEGEDE, A., JOSSA, R., YOUNG, T.L., RUBIO, F. y MARTINEZ, D., 2001. Projectant l'eix del Llobregat. Paisatge cultural i desenvolupament regional. Barcelona: UPC- MIT. ISBN 7653-793-X.

SAUER, C.O., 1925. The morphology of landscape. University of California Publications in Geography, vol. 2 (2), pp. 19-54. ISSN 0717-6554.

SUBIRATS, J. y RENDUELES, C., 2016. Los bienes comunes ¿Oportunidad o espejismo? Icaria Edi. Barcelona: s.n. ISBN 978-84-9888-736-5.

TATJER, M., URBIOLA, M. y GRUPO DE PATRIMONI INDUSTRIAL DEL FÒRUM DE LA RIBERA DEL BESÒS, 2005. Can Ricart. Estudi Patrimonial (Síntesi). 3W. Revista Bibliográfica de GEografía y Ciencias Sociales. UB, vol. X, $n^{\circ} 598$, no. Serie documental de Geo Crítica. 